\title{
Adubação nitrogenada e potássica na produtividade do capim Mombaça sobre adubação fosfatada
}

Álvaro José Gomes de FARIA ${ }^{[1]}$, Gilson Araújo de FREITAS ${ }^{[1 ; *]}$, Anderson Claiton Pereira GEORGETTI ${ }^{[1]}$, José Moises FERREIRA JÚNIOR ${ }^{[1]}$, Michelle Cristina Alves da SILVA ${ }^{[1]}$ e Rubens Ribeiro da SILVA ${ }^{[1]}$

${ }^{[1]}$ Universidade Federal do Tocantins; UFT, Campus Gurupi. Rua Badejós, Chácaras 69 e 72, Lote 07 Zona Rural $77402-970$ - Gurupi, Tocantins, Brasil._ajgomesdefaria@hotmail.com; anderson@uft.edu.br; juniortecagrofloresta11@hotmail.com; mcads.quimica@hotmail.com rrs2002@uft.edu.br

INFORMAÇÕES

Recebido em: $24 / 01 / 2015$

Aceito em: 30/07/2015

Publicado em: 27/09/2015

Document Object Identifier

$10.18607 / j b f s . v 2 i 3.24$

Termos de indexação:

Fósforo

Adubação de cobertura

Forrageira

Características morfológicas

*Autor para correspondência

araujoagro@hotmail.com

\section{RESUMO}

$\mathrm{O}$ atendimento das exigências nutricionais das plantas forrageiras é um dos fatores que interfere na produção e na qualidade das plantas. Diante disso, objetivou-se avaliar os efeitos da adubação nitrogenada e potássica em cobertura sobre as características morfológicas e produtivas da gramínea Panicum maximum cv. Mombaça cultivados sobre adubação fosfatada natural. O delineamento experimental adotado foi em blocos casualizados com quatro repetições. Obtendo assim um esquema fatorial com dois fatores $(6 \times 2)$. O primeiro fator foi composto por seis doses de adubação fosfatada $\left(0,35,70,140,210,280 \mathrm{~kg} \mathrm{ha}^{-1} \mathrm{de}_{2} \mathrm{P}_{2} \mathrm{O}_{5}\right)$ e o segundo fator está relacionado com a adubação de cobertura com nitrogênio e potássio. Quanto à adubação de cobertura, as parcelas que constituía uma área de $20 \mathrm{~m}^{2}$ foram divididas ao meio, sendo aplicados $100 \mathrm{~kg} \mathrm{ha}^{-1}$ de Ureia e $60 \mathrm{~kg} \mathrm{ha}^{-1}$ de Cloreto de Potássio. A ureia foi dividida em duas aplicações mensalmente de $50 \mathrm{~kg} \mathrm{ha}^{-1}$. A adubação de cobertura com nitrogênio e potássio, em função do aumento da dose da fonte de fosfato natural residual proporcionou resposta quadrática na maioria dos indicadores analisados. Observou-se que a maior altura, nos tratamentos com adubação de cobertura, foi de $100,6 \mathrm{~cm}$ de altura na dose $201,06 \mathrm{~kg}$ de $\mathrm{P}_{2} \mathrm{O}_{5} \mathrm{em}$ comparação com 74,9 $\mathrm{cm}$ de altura na dose de $165,7 \mathrm{~kg}$ de $\mathrm{P}_{2} \mathrm{O}_{5}$ sem adubação de cobertura. Assim, tanto a adubação fosfatada quanto a adubação de cobertura contribuíram para o desenvolvimento das plantas, podendo ser uma ferramenta importante para elevar os índices produtivos da forrageira.

\section{Nitrogen and potassium fertilization in grass productivity Mombasa about phosphorus fertilization}

\begin{abstract}
Meeting the nutritional requirements of forage plants is one of the factors that affect the production and quality of the plants. The research objective was to evaluate the achievements of nitrogen and potassium fertilization in coverage of the morphological and productive characteristics of the grass Panicum maximum cv. Mombasa grown on natural phosphate fertilizer. The experimental design was a randomized block with four replications. Thereby obtaining a factorial design with two factors (6 x 2). The first factor was composed of sixphosphorus fertilization $\left(0,35,70,140,210,280 \mathrm{~kg} \mathrm{ha}^{-1} \mathrm{P}_{2} \mathrm{O}_{5}\right)$ and the second factor was the topdressing with nitrogen and potassium. As for topdressing, parcels which was a $20 \mathrm{~m}^{2}$ area were divided in half, being applied 100 $\mathrm{kg} \mathrm{ha}^{-1}$ of urea and $60 \mathrm{~kg} \mathrm{ha}^{-1}$ Potassium Chloride. Urea was divided into two applications month $50 \mathrm{~kg} \mathrm{ha}^{-1}$. The topdressing nitrogen and potassium, due to the increase of residual phosphate rock supply dose provided quadratic response in most of the indicators. It was observed that the greater height, the top dressing treatments, was $100.6 \mathrm{~cm}$ at $201.06 \mathrm{~kg}$ dose of $\mathrm{P}_{2} \mathrm{O}_{5}$ and without topdressing was $74.9 \mathrm{~cm}$ in the dose of $165.7 \mathrm{~kg} \mathrm{P}_{2} \mathrm{O}_{5}$. Thus, both phosphorus fertilization as topdressing contributed to the development of plants and can be an important tool to increase the production rates of forage.
\end{abstract}

Index terms: phosphorus, topdressing, forage, morphological characteristics.

Copyright: () 2015 JBFS all rights. This is an open-access article distributed under the terms of the Creative Commons Attribution License, which permits unrestricted use, distribution, and reproduction in any medium, provided the original author and source are credited.

Financiamento: Os autores reportam que não houve suporte ou auxílio financeiro para a realização da pesquisa.

Conflito de interesse: Os autores declaram que não há conflito de interesse.

Como referir esse documento $(\mathrm{ABNT})$ :

FARIA, A.J.G.; FREITAS, G.A.; GEORGETTI, A.C.P.; FERREIRA JÚNIOR, J.M.; SILVA, M.C.A.; SILVA, R.R. da. Efeitos da adubação nitrogenada e potássica na produtividade do capim mombaça cultivados sobre adubação fosfatada. Journal of Bioenergy and Food Science, Macapá, v.2, n.3, p.98-106, jul./set., 2015. http://dx.doi.org/10.18607/jbfs.v2i3.24 


\section{INTRODUÇÃO}

O Brasil é o maior produtor mundial de bovinos a pasto, com aproximadamente 209 milhões de cabeças [1]. Temos aproximadamente 170 milhões de hectares de pastagens, sendo 100 milhões de pastagens cultivadas e 70 milhões de pastagens naturais [2]. No entanto, essas pastagens têm apresentado baixa capacidade de produção, suporte, manutenção e recuperação, caracterizandose assim, um quadro de pastagens degradadas [3, 4]. Isto contribui para que a pecuária tenha baixos índices zootécnicos, com baixas taxas de lotação e produtividade.

Cerca de $70 \%$ dos solos brasileiros cultivados apresentam limitação em fertilidade e o $\mathrm{P}$ é o elemento, cuja ausência limita mais frequentemente a produção das culturas nos solos de cerrado [5]. O modelo de produção de forragem adotado na pecuária brasileira vem contribuindo no processo de degradação da fertilidade do solo sob pastagens. $\mathrm{O}$ esgotamento da fertilidade do solo, em consequência da ausência de calagem e adubações de manutenção, tem sido apontado como uma das principais causas da degradação de pastagens cultivadas [6].

Portanto, para um bom manejo das pastagens, faz-se necessário uma boa adubação de estabelecimento e manutenção. A adubação nitrogenada e potássica aliada a adubação fosfatada natural podem ser utilizados para elevar a produção e qualidade da forrageira. O fósforo é utilizado na adubação de estabelecimento atuando no metabolismo das plantas, desempenhando papel importante na fotossíntese, na respiração, no metabolismo de açúcares, na divisão celular e no alargamento das células. Seu suprimento adequado promove $\mathrm{o}$ uso mais eficiente da água $\mathrm{e}$, consequentemente, dos outros nutrientes como o nitrogênio e o potássio [7, 8].

. O nitrogênio é o mais impactante em termos de ganhos, na produção de forragem. Sua aplicação é de fundamental importância para a manutenção da produtividade e da sustentabilidade da pastagem, sendo sua deficiência considerada um fator importante para desencadear o processo de degradação [9]. A principal função desse nutriente e ser e constituinte das proteínas e interfere diretamente no processo fotossintético [10]. Além disso, para que possa ser usado como ferramenta estratégica para maximizar a produção de forragem nos sistemas intensivos de produção, o solo deve estar devidamente corrigido e suprido com fósforo (P) e outros macro como o potássio e micronutrientes [11].
O potássio $(\mathrm{K})$, por sua vez, também pode limitar a resposta da produção de forrageiras de maior exigência nutricional, especialmente em sistemas intensivos, onde as relações inadequadas dos nutrientes podem prejudicar a nutrição mineral das plantas [11]. Esse nutriente participa direta ou indiretamente de inúmeros processos bioquímicos envolvidos com o metabolismo de carboidratos, como a fotossíntese e a respiração, e sua carência reflete-se numa baixa taxa de crescimento [12].

Há uma grande importância em estudos com adubação de cobertura em pastagens no cerrado. Essa importância reside principalmente em fatos como: a maioria dos solos brasileiros são pobres em nitrogênio, fosforo e potássio [13], é imprescindível o aprimoramento de técnicas para aumentar a utilização deste nutriente, sem, contudo, elevar os custos de produção [14], além de determinar os níveis considerados ideais para uma maior eficiência na adubação e conseguintemente maior produtividade.

Diante da importância de se fazer uma boa adubação de cobertura na manutenção das pastagens e com isso obter melhor produtividade e qualidade, objetivou-se com esse trabalho avaliar os feitos da adubação nitrogenada e potássica em cobertura sobre as características morfológicas e produtivas da gramínea Panicum maximum cv. Mombaça cultivados sobre adubação fosfatada natural.

\section{MATERIAL E MÉTODOS}

O presente estudo foi conduzido na área experimental da Universidade Federal do Tocantins (UFT), Campus Universitário de Gurupi, localizado na região sul do Estado do Tocantins, a $280 \mathrm{~m}$ de altitude, nas coordenadas " $11^{\circ} 43$ ' 45 " de latitude e $49^{\circ} 04^{\prime} 07^{\prime \prime}$ de longitude. A temperatura média anual é de $29,5^{\circ} \mathrm{C}$, com precipitação média anual de 1804 $\mathrm{mm}$. O solo onde foi implantado o experimento é Neossolo Quartzarênico Órtico de acordo com a metodologia de classificação de solos desenvolvida pela EMBRAPA [15].

O experimento foi conduzido em delineamento experimental de blocos casualizados com quatro repetições. Os tratamentos foram obtidos em arranjo fatorial com dois fatores $(6 \times 2)$. $\mathrm{O}$ primeiro fator são seis doses de adubação fosfatada $\left(0,35,70,140,210,280 \mathrm{~kg}\right.$ de $\left.\mathrm{P}_{2} \mathrm{O}_{5}\right)$ e o segundo fator é a adubação de cobertura com o nitrogênio e potássio.

As parcelas experimentais foram definidas com as dimensões de $4 \times 5 \mathrm{~m}$ (largura e comprimento, respectivamente) e espaçadas por um 
metro de corredor, totalizando uma área de $20 \mathrm{~m}^{2}$ por parcela. $\mathrm{O}$ experimento foi avaliado no período chuvoso (janeiro a março).

A adubação de estabelecimento da pastagem foi através fonte de $\mathrm{P}_{2} \mathrm{O}_{5}$, fosfato natural, cuja composição é $24 \%$ de $\mathrm{P}_{2} \mathrm{O}_{5}$ total e em torno de 23 a $27 \%$ de $\mathrm{Ca}^{2+}$. As doses do $\mathrm{P}_{2} \mathrm{O}_{5}$ são equivalentes a 145,$83 ; 291,66 ; 583,33 ; 875$ e $1166,66 \mathrm{~kg} \mathrm{ha}^{-1}$ de fosfato natural. $\mathrm{O}$ plantio foi realizado manualmente a lanço, assim como a aplicação da fonte de fósforo, buscando uniformização na aplicação.

A forrageira utilizada foi o capim Mombaça (Panicum maximum cv. Mombaça) selecionada devido a sua alta capacidade produtiva de forragem e lâminas foliares, trata-se de uma gramínea tropical de porte elevado, com perfilhos vigorosos, alto valor nutricional, tolerância alta a seca, resistência média a cigarrinha das pastagens e a capacidade em responder adubação aplicada com resultados muito satisfatórios. A quantidade de sementes aplicada nas parcelas foi calculada de acordo com o valor cultural (VC) do capim Mombaça.

Depois de dois anos da implantação do experimento, as parcelas foram divididas ao meio, onde foram aplicados $100 \mathrm{~kg} \mathrm{ha}^{-1}$ de Ureia, cuja composição é $44 \%$ de $\mathrm{N}$, e $60 \mathrm{~kg} \mathrm{ha}^{-1}$ de cloreto de potássio, cuja composição é $58 \%$ de $\mathrm{K}^{+}$. O nitrogênio foi dividido em duas aplicações de $50 \mathrm{~kg}$ ha ${ }^{-1}$, a segunda aplicação foi feita um mês após a primeira. A adubação de cobertura foi realizada a lanço.

Para avaliar a importância do adequado suprimento de nitrogênio e potássio na produção e qualidade de forragem foram avaliados os seguintes indicadores de produção: Altura da planta (AP), Número de Perfilho (NP), Massa verde da parte aérea (MSPA) e Massa seca da parte aérea (MSPA).

A altura de planta foi mensurada em cada parcela com régua graduada em milímetros em seis pontos distintos, sendo três pontos na metade da parcela com a adubação de cobertura e três pontos na metade da parcela sem a adubação de cobertura para que futuramente pudesse ser feita a comparação dentro da parcela, mensurada do solo até a extremidade das folhas.

A quantidade de perfilhos e a determinação da matéria verde na pastagem foi realizada com auxílio de um quadrado metálico de dimensões conhecidas de $0,5 \times 0,5 \mathrm{~m}$, que foi lançado quatro vezes nas parcelas aleatoriamente sendo duas na metade da parcela com a adubação de cobertura e duas na metade da parcela sem adubação de cobertura e posteriormente ceifadas a $30 \mathrm{~cm}$ do solo com auxílio de cutelo. Após a colheita as amostras foram identificadas e na sequência realizadas as contagens manuais dos perfilhos em cada amostra coletada, por fim todas as amostras foram embaladas em sacos de papel, posteriormente foram pesadas em balança de precisão para determinação da matéria verde e logo após foram secas em estufa de circulação forçada à temperatura entre 60 e 65 ${ }^{\circ} \mathrm{C}$ por 72 horas visando à determinação de massa seca da parte aérea das forragens.

Com os resultados obtidos nas avaliações dos seis níveis de adubação na presença e na ausência de nitrogênio e potássio foram submetidos à análise de regressão, avaliando a significância dos betas e dos coeficientes de determinação utilizando o programa Statística versão 7.0 [16]. Os gráficos das regressões foram plotados utilizando o programa estatístico SigmaPlot versão $10^{\circledR}$ [17].

\section{RESULTADOS E DISCUSSÃO}

\section{Altura da Planta (AP)}

A adubação de cobertura com nitrogênio e potássio, em função do aumento da dose da fonte de fosfato natural residual proporcionou resposta quadrática significativa na altura das plantas de capim Mombaça. Os resultados indicam que a falta de adubação de cobertura mostra-se um fator limitante ao crescimento da pastagem na condição estudada (período chuvoso), ou seja, mesmo em solos com boa disponibilidade de fósforo residual, a falta da adubação de cobertura proporcionou um declínio de 25,5\% na altura de plantas em relação as que receberão adubação de cobertura. A maior altura de planta, observada nos tratamentos sob adubação de cobertura, foi de 100,6 $\mathrm{cm}$ na dose $201,06 \mathrm{~kg}$ de $\mathrm{P}_{2} \mathrm{O}_{5}$. Foi observado, também, que houve comportamento quadrático significativo na altura de plantas para a condição sem cobertura, com $74,9 \mathrm{~cm}$ na dose de $165,7 \mathrm{~kg}$ de $\mathrm{P}_{2} \mathrm{O}_{5}$ (Figura 1).

O efeito positivo da adubação nitrogenada $\mathrm{e}$ potássica podem ser percebidos, na redução do período de descanso entre os pastejo, nos sistemas rotacionais, de 28,3 para 21,07 dias com o fosfato natural e a adubação de cobertura. Isso significa uma redução anual de 107,16 dias para o fosfato natural (residual) com a adubação nitrogenada e potássica. 


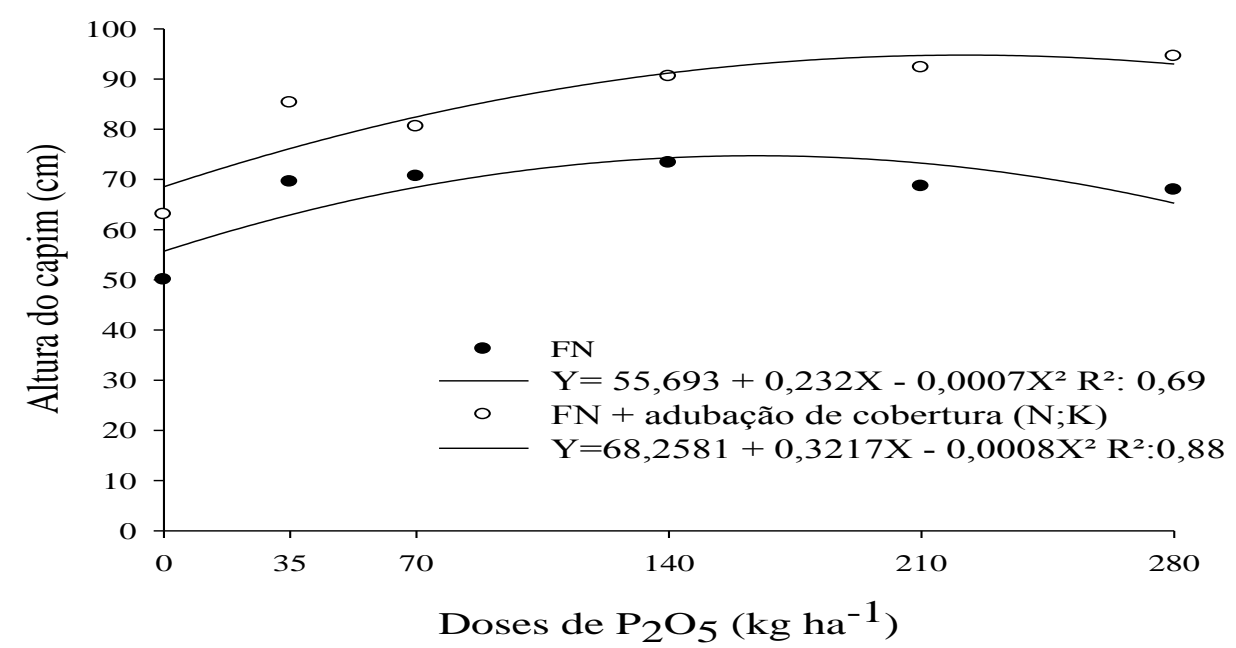

Figura 1. Altura de planta de Panicum maximum cv. Mombaça sob o efeito da adubação nitrogenada e potássica em cobertura em áreas adubadas com fosfato natural.

O nitrogênio é o potássio são os nutrientes extraídos em maiores quantidades pelas plantas. A combinação desses nutrientes assume papel importante na nutrição, e podem afetar os atributos morfogêneticos, produtivos e nutricionais do Panicum maximum cv. Mombaça [10].

Cunha, Santos e Araújo [18] avaliando a cobertura do solo e altura do capim-xaraés em diferentes estações anuais, intervalos de desfolha e manejos de adubação, observaram que as doses de adubação tiveram uma relação entre nitrogênio e potássio de $1 \mathrm{~N}: 0,8 \mathrm{~K}_{2} \mathrm{O}$ e foram de $0,15,39,64$, 83 e $100 \%$ da referência $(700$ e $560 \mathrm{~kg}$ de $\mathrm{N}$ e $\mathrm{K}_{2} \mathrm{O}_{5}$ ) que variaram de 33,6 a $91,5 \mathrm{~cm}$, no manejo de adubação nitrogenada e potássica convencional a lanço.

Em trabalho realizado por Freitas [19] com o emprego de altas doses de nitrogênio (100 e $133 \mathrm{~kg}$ há $^{-1}$ corte $\left.^{-1}\right)$, observou-se que a forrageira foi colhida com aproximadamente 25 e 28 dias de idade, respectivamente. Já a adubação com doses menores $\left(0\right.$ e $33 \mathrm{~kg} \mathrm{ha}^{-1}$ corte $\left.^{-1}\right)$ de nitrogênio, o período de corte da forrageira foi a partir dos 46 dias. Dessa forma, para uma mesma altura de corte, plantas sob maiores doses de nitrogênio apresentaram menor idade na colheita. Os dados obtidos nesta pesquisa corroboram com essas informações.

Quando é avaliada a altura das plantas em resposta a uma adubação nitrogenada, o crescimento da planta pode ser explicado pelo provável incremento no número de células em processo de divisão, estimulando a produção de novas células e proporcionando aumento na taxa de alongamento de folhas, o que pode contribuir para mudanças no tamanho da lâmina foliar [20].
Segundo Rodrigues et al [21], adubações com potássio resultam em altura superior de toda planta devido ao aumento da eficiência da fotossíntese, ao aumento da resistência a algumas doenças e a ótima eficiência do uso da água.

\section{Número de Perfilhos (NP)}

Para a variável número de perfilhos da forrageira em função do aumento da dose da fonte de fosfato natural, o capim Mombaça apresentou comportamento linear com a aplicação de nitrogênio e potássio em cobertura, obtendo assim 56 perfilhos numa área de $0,25 \mathrm{~m}^{2}$, com uma dose máxima de $280 \mathrm{~kg}$ de $\mathrm{P}_{2} \mathrm{O}_{5}$. Apresentando um incremento de $28,6 \%$ em relação as plantas que não receberam adubação de cobertura. Este resultado mostra que a forrageira ainda não alcançou sua máxima produção em relação aos perfilhos, podendo assim obter maior numero em doses superior a $280 \mathrm{~kg}$ de $\mathrm{P}_{2} \mathrm{O}_{5}$ ha $^{-1}$ aliado a adubação de cobertura. Contudo, nas plantas que não foram aplicadas o nitrogênio e potássio observou-se comportamento quadrático significativo, com menores números de perfilhos com a produção máxima de 40 perfilhos numa área de $0,25 \mathrm{~m}^{2}$, com a dose de $238,0 \mathrm{~kg}$ de $\mathrm{P}_{2} \mathrm{O}_{5}$ (Figura 2).

O perfilhamento de gramíneas forrageiras é importante para produção de biomassa e representa uma das mais importantes características para o estabelecimento das plantas e da produtividade de pastagens. Segundo Maya et al [22], o aumento no número de perfilhos de gramíneas forrageiras promove um maior incremento na produção de massa seca das pastagens. 


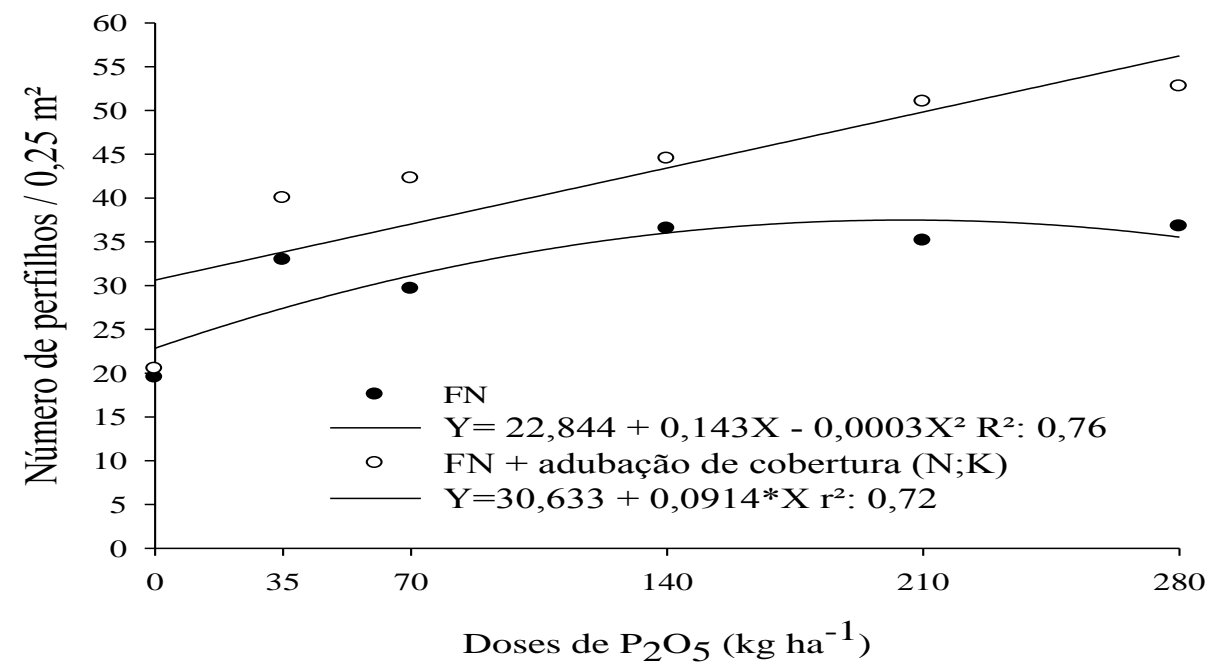

Figura 2. Números de perfilhos de plantas de Panicum maximum cv. Mombaça sob o efeito da adubação nitrogenada e potássica em cobertura em áreas adubadas com fosfato natural.

No trabalho de Mesquita, Neres e Oliveira [23], as doses de P elevaram o número de perfilhos das gramíneas estudadas, sendo que a Brachiaria hibrida cv. Mulato apresentou maior densidade de perfilhos. Para Cabral, Souza e Alexandrino [24] avaliando as características estruturais e agronômicas da Brachiaria brizantha cv.Xaraés submetida a doses de nitrogênio, efeito quadrático das doses de nitrogênio foi verificado sobre o número de perfilhos $0,15 \mathrm{~m}^{-2}$, para as doses de 270 e $401 \mathrm{~kg} \mathrm{ha}^{-1}$ de nitrogênio, respectivamente. $\mathrm{O}$ aumento no número de perfilhos foi de 89 e $87 \%$ em relação ao capim não adubado.

Pereira [25] avaliou o efeito do fornecimento de potássio na solução nutritiva para o perfilhamento do capim mombaça e constatou que as doses de potássio tiveram efeito significativo no número de perfilhos em dois períodos de avaliação de crescimento do capim. Verificou que o maior número de perfilhos, foi obtido com a dose de potássio igual ou superior a $234 \mathrm{mg} \mathrm{L}^{-1}$ no primeiro corte e igual a $468 \mathrm{mg} \mathrm{L}^{-1}$ no final do segundo corte.

\section{Massa Verde da Parte Aérea (MVPA)}

As plantas do tratamento que receberam aplicação de nitrogênio e potássio em cobertura em função do aumento da dose de fosfato natural proporcionou aumento na massa verde da parte aérea da planta forrageira, apresentando comportamento quadrático significativo. A produção máxima de massa verde alcançada foi de
$0,339 \mathrm{~kg} \mathrm{ha}^{-1}$ numa área de $0,25 \mathrm{~m}^{2}$ com a dose de $203,88 \mathrm{~kg}$ de $\mathrm{P}_{2} \mathrm{O}_{5}$ apresentando um incremento de $27 \%$ em relação às plantas que não receberam adubação de cobertura. Já plantas que não foram aplicadas a adubação de cobertura também observou-se comportamento quadrático significativo com menores valores de massa verde com a produção máxima de $0,247 \mathrm{~kg} \mathrm{ha}^{-1}$ numa área de $0,25 \mathrm{~m}^{2}$ com a dose de $214,58 \mathrm{~kg}$ de $\mathrm{P}_{2} \mathrm{O}_{5}$ (Figura 3).

No entanto, pode se observar que os processos de formação e desenvolvimento de folhas são fundamentais para o crescimento vegetal e produção de massa verde das pastagens. Apesar do potencial de produção de uma planta forrageira ser determinado geneticamente [26], este pode ser influenciado pelas condições do meio, como temperatura, radiação, umidade, luminosidade, disponibilidade de nutrientes e água [27].

Martha Júnior, Vilela e Barcellos [28] relataram que na produção de forragem o uso de fertilizante depende de fatores como as doses de nitrogênio, o emprego dos outros nutrientes, o histórico da área (que inclui o efeito residual das adubações), o manejo da pastagem, a estratégia de manejo do nitrogênio-fertilizante adotada, e as características de clima e de solo da região, que interferem tanto na capacidade da planta em responder ao fertilizante nitrogenado como na recuperação e perda do nitrogênio-fertilizante aplicado. 


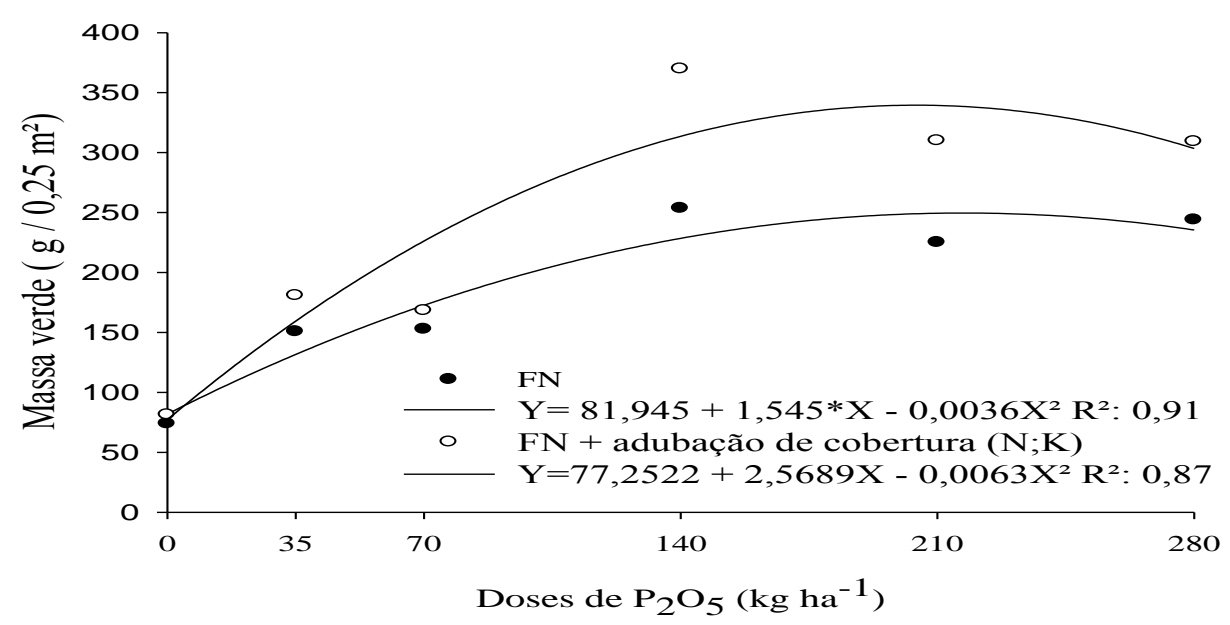

Figura 3. Produção de Massa Verde de plantas de Panicum maximum cv. Mombaça sob o efeito da adubação nitrogenada e potássica em cobertura em áreas adubadas com fosfato natural.

O nitrogênio, dentre os diversos outros aspectos que interferem na produção da massa da forragem, é o principal elemento responsável por essa produção e, consequentemente a produção animal. Ele é o responsável pelo início da rebrota das plantas juntamente com os carboidratos de reserva, desde o início do desenvolvimento da planta influenciando a produtividade das pastagens [29]. A maior produção de matéria verde e matéria seca é em parte consequência do incremento no número de folhas por perfilho e na altura da forragem.

\section{Massa Seca da Parte Aérea (MSPA)}

A forrageira em função do aumento da dose de fosfato natural apresentou comportamento linear positivo com a aplicação de nitrogênio e potássio em cobertura, influenciando na produção de massa seca das plantas. A máxima resposta em MSPA em função do aumento da dose da fonte de fosfato natural residual foi obtida na dose de $280 \mathrm{~kg}$ de $\mathrm{P}_{2} \mathrm{O}_{5} \mathrm{ha}^{-1}$, dose na qual as plantas atingiram uma produção máxima de $0,123 \mathrm{~kg} \mathrm{ha}^{-1}$ numa área de $0,25 \mathrm{~m}^{2}$ apresentando um incremento de aproximadamente $18,7 \%$ em relação a testemunhas. Contudo a parcela sem a aplicação de nitrogênio e potássio foi observado comportamento quadrático na produção de massa seca, com a produção máxima de $0,100 \mathrm{~kg} \mathrm{ha}^{-1}$ de massa seca numa área de $0,25 \mathrm{~m}^{2}$, com a dose de $218,33 \mathrm{~kg} \mathrm{ha}^{-}$ ${ }^{1} \mathrm{de} \mathrm{P}_{2} \mathrm{O}_{5}$. (Figura 4)

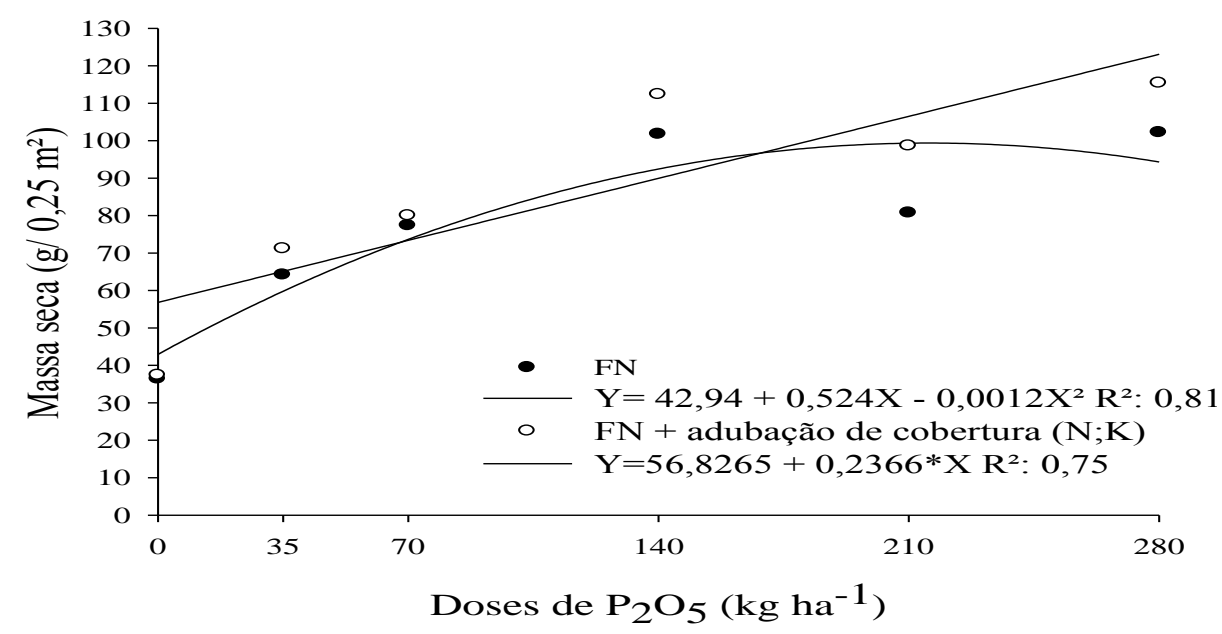

Figura 4. Produção de Massa Seca de plantas de Panicum maximum cv. Mombaça sob o efeito da adubação nitrogenada e potássica em cobertura em áreas adubadas com fosfato natural.

Costa et al [30] também encontraram efeito linear do nitrogênio sobre a produção de massa seca de cultivares de Brachiaria brizantha (Marandu, Xaraés e MG-4), enquanto que Santos et al [34] ao 
estudarem pastos diferidos de capim branquearia adubados com nitrogênio observaram que as massas de forragem total e dos seus componentes morfológicos aumentaram de forma linear com o aumento do período de diferimento e das doses de nitrogênio.

Cabral et al [24] estudando as características estruturais e agronômicas da Brachiaria brizantha cv. Xaraés submetida a doses de nitrogênio, observou que para a maior dose utilizada $333,3 \mathrm{~kg}$ $\mathrm{ha}^{-1} \mathrm{de} \mathrm{N}$, a massa seca foi de $6,24 \mathrm{t} \mathrm{ha}^{-1}$. Essa massa foi acumulada em crescimento livre dentro do intervalo de 35 dias, podendo-se a partir daí inferir que houve o acúmulo de forragem de $178,28 \mathrm{~kg}$ ha ${ }^{1}$ dia $^{-1}$ de massa seca no período das águas. $\mathrm{O}$ aumento na massa seca foi de $87,5 \%$ para a maior dose de nitrogênio em comparação ao tratamento testemunha que foi de 3,32 $\mathrm{t} \mathrm{ha}^{-1} \mathrm{de} \mathrm{MS}$, sendo a eficiência de uso do nitrogênio convertida em 8,73 $\mathrm{Kg} \mathrm{ha}^{-1}$ de massa seca para cada $\mathrm{kg}$ de nitrogênio aplicado.

Resultado parecido também foi encontrado por Costa et al [31], onde avaliando o efeito de doses de nitrogênio e potássio na produção de massa seca do capim Xaraés, verificaram resposta linear na produção de massa seca, quando comparam os resultados na testemunha, com as mais altas doses de nitrogênio e potássio, com incremento na produção de massa seca de $8,6 \%$ e $19,2 \%$ respectivamente.

Vários trabalhos [32, 33, 34, 35] evidenciaram influência do $\mathrm{N}$ no aumento da produção de matéria seca em razão, principalmente, do maior perfilhamento.

Diante de tudo que foi exposto pode observar a grande importância de se fazer adubação de

\section{REFERÊNCIAS}

[1]. ABIEC. Associação Brasileira das Indústrias Exportadoras de Carnes. Rebanho Bovino Brasileiro, 2014. Disponível em: <http://www.abiec.com.br/3 rebanho.asp $>$. Acessado em: 18 de jan. de 2015.

[2]. IBGE. Instituto brasileiro de geografia e estatística. Sidra - Banco de dados agregados. Brasília:, 2012. Disponível em: <http://www.sidra.ibge.gov.br/bda/>. Acesso em: 20 set. 2012.

[3]. CAVALLINI, M.C.; ANDREOTTI, M.; OLIVEIRA, L.L.; PARIZ, C.M.; CARVALHO, M. P. Relações entre produtividade de Brachiaria brizantha e atributos físicos de um Latossolo do Cerrado. Revista Brasileira de Ciência do Solo, v.34, n.4, p.1007-1015, 2010. cobertura com nitrogênio e potássio nas pastagens, essa adubação de cobertura pode incrementar linearmente todas as características morfológicas das plantas, no entanto e preciso que todos os nutrientes requeridos pela planta estejam em perfeito equilíbrio no solo (lei do mínimo), respeitando essa lei pode se obter grandes produtividades.

\section{CONCLUSÃO}

Após dois anos da implantação da forrageira, a adubação de estabelecimento com fosfato natural, ainda proporcionou aumento na produtividade do capim Panicum maximum cv. Mombaça.

A adubação de cobertura com nitrogênio e potássio otimizou a produção do capim, proporcionando aumentos significativos em todas as características morfogênicas estudadas, sugerindo que sua utilização pode ser benéfica para elevar índices produtivos e melhorar a qualidade nutricional das pastagens.

\section{CONTRIBUIÇÃO AUTORES}

1. Condução e avaliação do experimento, análises estatísticas e elaboração do artigo:

Álvaro José Gomes de Faria, Anderson Claiton Pereira Georgetti, José Moises Ferreira Júnior e Michelle Cristina Alves da Silva

2. Planejamento, orientação e revisão final do artigo: Silva.

Gilson Araújo Freitas e Rubens Ribeiro da

[4]. FERNANDES, L. O.; REIS, R. A.; PAES, J. M. V. Efeito da suplementação no desempenho de bovinos de corte em pastagem de Brachiaria brizantha cv. Marandu. Ciência \& Agrotecnologia, v.34, n.1, p.240-248, 2010.

[5]. SANTOS, H.Q.; FONSECA, D.M.; CANTARUTTI, R.B.; ALVAREZ, V.H.; NASCIMENTO JUNIOR, D. Níveis críticos de fósforo no solo e na planta para gramíneas forrageiras tropicais, em diferentes idades. Revista Brasileira de Ciência do Solo, v.26, p.173-182, 2002.

[6]. MENEZES, J.F.S; FREITAS, K.R; CARMO, M.L.; SANTANA, R.O; FREITAS, M.B.DE; PERES, L. C. Produtividade de massa seca de forrageiras adubadas com cama de frango e dejetos líquidos de suínos. I Simpósio Internacional sobre Gerenciamento de Resíduos de Animais. Anais... Março de 2009, pag. 322 a 327. 
[7]. SOUSA, D.M.G.; LOBATO, E. Adubação com nitrogênio. In: SOUSA, D.M.G.; LOBATO, E. (Eds.) Cerrado - correção do solo e adubação. 2.ed. Brasília: EMBRAPA. p.129-145, 2004.

[8]. GUIMARÃES, P.T.G. Adubação do cafeeiro e a quantidade do produto colhido. Informe agropecuário, Belo Horizonte, v.32, n.261, p. 3951, 2011.

[9]. VIANA, M.C.M.; FREIRE, F.M.; FERREIRA, J.J.; MACÊDO, G.A.R.; CANTARUTTI, R.B.; MASCARENHAS, M.H.T. Adubação nitrogenada na produção e composição química do capimbraquiária sob pastejo rotacionado. Revista Brasileira de Zootecnia, v. 40, n. 7, p. 1497-1503, 2011.

[10]. MEGDA, M.M.; Suprimento de nitrogênio e de potássio e características morfogênicas, nutricionais e produtivas do capim- Marandu. 2009. 84f. Dissertação de mestrado Universidade de São Paulo (USP), Piracicaba-SP, 2009.

[11]. BERNARDI, A.C.C.; RASSINI, J.B. Produção de matéria seca pelo capim-tanzânía em função de doses e relações de nitrogênio e potássio. In: REUNIÃO BRASILEIRA DE FERTILIDADE DO SOLO E NUTRIÇÃO DE PLANTAS, 28, 2008, Londrina. Anais... Desafios para o uso do solo com eficiência e qualidade ambienta1. Londrina: Embrapa Soja: SBCS, 2008. 1 CDROM.

[12]. SIMILI, F.F.; GOMIDE, C.A.M.; MOREIRA, A.L.; REIS, R.A.; LIMA, M.L.P.; PAZ, C.C.P. Respostas do híbrido de sorgo-sudão às adubações nitrogenada e potássica: características estruturais e produtivas. Ciência \& Agrotecnologia, v.34 n.1, p.87-94, 2010.

[13]. VILELA, H. Séries Gramíneas TropicaisGênero Panicum (Panicum Maximum Mombaça Capim). 2008

[14]. CECATTO, U., SKROBOT, V.D., FAKIR, G.M., JOBIM, C.C., BRANCO, A.F., GALBEIRO, S. e JANEIRO, V. Características morfogênicas do capim mombaça (Panicum maximum Jacq. cv. Mombaça) adubado com fontes de fósforo, sob pastejo. Revista Brasileira de Zootecnia, v.36, p.1699-1706, 2007.

[15]. EMBRAPA. Empresa Brasileira de Pesquisa Agropecuária. Centro Nacional de Pesquisa de Solos. Sistema Brasileiro de Classificação de Solos. 2. ed. Rio de Janeiro: Embrapa Solos, 2006.

[16]. STATSOFT Inc. 2004, 25 de fevereiro. Statística (data analysis software system), version 7.0. Disponível em: $<$ http://www.statsoft.com $>$. Acessado em 18 de ago. de 2014.

[17]. SYSTAT. 2014, 25 de fevereiro. Manual de uso do Sigmaplot 10, Windows. Disponível em 〈http://www.systat.com/products/sigmaplot>. Acessado em 18 de ago. 2014.

[18]. CUNHA, O.F.R.; SANTOS, A.C.; ARAÚJO, L.C. Produtividade do Panicum maximum (MOMBAÇA) em função de diferentes níveis de nitrogênio. Revista da FZVA. Uruguaiana, v.17, n.1, p. 136-145. 2010.
[19]. FREITAS, F.P. Produção e valor nutritivo do capim-tanzânia sob doses de nitrogênio e densidades de plantas. 2009, 65f. Dissertação (Mestrado em Zootecnia) - Universidade Federal de Viçosa, Viçosa, MG, 2009.

[20]. FAGUNDES, J.L.; FONSECA, D.M.; MISTURA, C.; MORAIS, R.V.; VITOR, C.M.T.; GOMIDE, J.A.; DOMICIO, N.J.; CASAGRANDE, D.R.; COSTA, L.T. Características morfogênicas e estruturais do capim-braquiária em pastagem adubada com nitrogênio avaliadas nas quatro estações do ano. Revista Brasileira de Zootecnia, v.35, p. 21-29, 2006.

[21]. RODRIGUES, R.C.; MOURÃO, G.B.; BRENNECKE, K.; LUZ, P.H.C.; HERLING, V.R. Produção de massa seca, relação folha/colmo e alguns índices de crescimento do Brachiaria Brizantha cv. Xáraes cultivado com a combinação de doses de nitrogênio e potássio. Revista Brasileira de Zootecnia, v.37, n.3, p.394-400, 2008.

[22]. MAYA, F.L.A.; CABRAL, S.B.; SANTOS; P.M.; CORSI, M. Determinação da produçãode matéria seca ao longo do estabelecimento do capim Tanzânia ("Panicum maximum" Jacq.): densidade populacional de perfilhos $\mathrm{x}$ massa por perfilho. In: REUNIÃO ANUALDA SOCIEDADE BRASILEIRA DE ZOOTECNIA, 38, 2001, Piracicaba. Anais... Piracicaba:SBZ, p. 143-144. 2001.

[23]. MESQUITA, E.E.; NERES, M.A.; OLIVEIRA, P.S.R. et al. Teores críticos de fósforo no solo e características morfogênicas de Panicum maximum cultivares Tanzânia e Mombaça e Brachiaria hibrida Mulato sob aplicação de fósforo. Revista Brasileira de Saúde e Produção Animal, v.11, n.2, p.292-302, 2010.

[24]. CABRAL, W.B; $\quad$ SOUZA, A.L.; ALEXANDRINO, E. Características estruturais e agronômicas da Brachiaria brizantha cv. Xaraés submetida a doses de nitrogênio. Revista Brasileira de Zootecnia, v.41, n.4, p.846-855, 2012.

[25]. PEREIRA, W.L.M. Doses de potássio e de magnésio em solução nutritiva para o capimMombaça. Piracicaba, 2001. 128p. Tese (Doutorado) - Escola Superior de Agricultura "Luiz de Queiroz" Universidade de São Paulo, 2001.

[26]. FAGUNDES, L.J.; FONSECA, D.M.; GOMIDE, J.A.; NASCIMETO JÚNIOR, D.; VITOR, C.M. T.; MORAIS, R.V.; MISTURA, C.; REIS, G.C.; MARTUSCELLO, J.A. Acumulo de forragem em pastos de Brachiaria Decubens adubadas com nitrogênio. Pesquisa Agropecuária Brasileira, v.40, n.4, p397-403, 2005.

[27]. LUPATINI, G.C.; HERNANDEZ, F.B.T. Irrigando Pastagens para melhor produção. A voz do povo. Ilha Solteira, 357 ed. ano V, p. 2, 24 jan. 2006.

[28]. MARTHA JÚNIOR, G.B.; VILELA, L; BARCELLOS, A.O.A planta forrageira e o agroecossistema. In: SIMPÓSIO SOBRE 
MANEJO DA PASTAGEM, 23, 2006, Piracicaba. Anais... Piracicaba: FEALQ, p. 87-137, 2006.

[29]. CECATO, U.; GABEIRO, S; PARIS, W; SOARES FILHO, C.V.; TEIXEIRA, S. Uso de Nitrogênio em Pastagem. Anais... Simpósio de Produção Animal a Pasto. p. 117-161, 2011.

[30]. COSTA, K.A.P.; OLIVEIRA, I.P.; FAQUIN, V.; SILVA, G.P.; SEVERIANO, E.C. Produção de massa seca e nutrição nitrogenada de cultivares de Brachiaria brizantha (A. Rich) Stapf sob doses de nitrogênio. Ciência \& Agrotecnologia, v.33, n.6, p.1578- 1585, 2009.

[31]. COSTA, K.A.P.; FAQUIN, F.; OLIVEIRA, I.P.; ARAÚJO, J.L.; RODRIGUES, R.B. doses e fontes de nitrogênio em pastagem de capim-murandu. IINutrição nitrogenada da planta. Revista Brasileira de Ciência do solo, viçosa, v.32, p.1601-1607, 2008.

[32]. ALEXANDRINO, E.; NASCIMENTO JUNIOR, D.; MOSQUIM, P.R.; REGAZZI, A.J.; ROCHA, F.C. Características morfogênicas e estruturais na rebrotação da Brachiaria brizantha cv.Marandu submetida a três doses de nitrogênio. Revista Brasileira de Zootecnia, v. 33, n. 6, p. 1372-1379, 2004.

[33]. QUADROS, F.L.F.; BANDINELLI, D.G. Efeitos da adubação nitrogenada e de sistemas de manejo sobre a morfogênese de Lolium multiflorum Lam, e Paspalum urvillei Steud, em ambiente de várzea. Revista Brasileira de Zootecnia, v. 34, n. 1, p. 44-53, 2005.

[34]. SANTOS, M.E.R.; FONSECA, D.M.; BALBINO, E.M.; MONNERAT, J.P.I.S.; SILVA, S.P. Capim braquiária diferido e adubado com nitrogênio: produção e características da forragem. Revista Brasileira de Zootecnia, v. 38, n. 4, p. 650-656, 2009.

[35]. ROMA, C.F.C.; CECATO, U.; SOARES FILHO, C.V; SANTOS, G.T.; RIBEIRO, O.S.; IWAMOTO, B.S. Morphogenetic and tillering dynamics in Tanzania grass fertilized and nonfertilized with nitrogen according to season. Revista Brasileira de Zootecnia, v.41, n.3, p.565573, 2012. 